\title{
On-pump beating heart versus conventional on-pump coronary artery bypass grafting on clinical outcomes: a meta-analysis
}

\author{
Chen Wang", Yefan Jiang", Xionggang Jiang, Si Chen \\ Department of Cardiovascular Surgery and Heart transplantation, Union Hospital, Tongji Medical College, Huazhong University of Science and \\ Technology, Wuhan, China \\ Contributions: (I) Conception and design: C Wang, Y Jiang; (II) Administrative support: None; (III) Provision of study materials or patients: None; (IV) \\ Collection and assembly of data: C Wang, Y Jiang; (V) Data analysis and interpretation: All authors; (VI) Manuscript writing: All authors; (VII) Final \\ approval of manuscript: All authors. \\ "These authors contributed equally to this work. \\ Correspondence to: Si Chen, MD, PhD; Xionggang Jiang, PhD. Department of Cardiovascular Surgery and Heart transplantation, Union Hospital, \\ Tongji Medical College, Huazhong University of Science and Technology, Wuhan 43000, China. \\ Email: sichen@hust.edu.cn; jiangxionggang@hotmail.com.
}

Background: A hybrid surgery method, on-pump beating heart coronary artery bypass graft (ON$\mathrm{BH}$ CABG), is supposed to be a promising technology for coronary artery revascularization. Here, we conducted a comprehensive meta-analysis of the data derived from published studies on ON-BH CABG and conventional on-pump coronary artery bypass graft (C-CABG) to compare their short-term and long-term clinical outcomes.

Methods: We searched major electronic databases and 24 studies incorporating 6,862 patients $(1,847 \mathrm{ON}-$ BH CABG and 5,015 C-CABG) were included eventually, and 9 studies of them were focusing on high-risk patients.

Results: Compared with ON-BH CABG, C-CABG was associated with a higher risk in early mortality [odds ratio (OR), 1.45; 95\% confidence interval (CI), 1.09 to 1.93 ; $\mathrm{P}=0.01$ ], myocardial infarction (MI) (OR, 2.60; 95\% CI, 1.41 to 4.78; $\mathrm{P}<0.01)$, low output syndrome (LOS) (OR, 2.56; 95\% CI, 1.55 to $4.23 ; \mathrm{P}<0.01)$, renal failure (OR, 1.84; $95 \% \mathrm{CI}, 1.38$ to $2.44 ; \mathrm{P}<0.01)$. In contrast, there was no significant difference in long-term survival [hazard ratio (HR), 1.08; 95\% CI, 0.81 to $1.43 ; \mathrm{P}=0.60$ ]. In systematic analysis of the studies in highrisk patients, ON-BH CABG showed a lower risk in terms of early mortality, intra-aortic balloon pump (IABP) usage, renal failure, hemodialysis, $\mathrm{MI}$ and pulmonary complication. No significant difference was observed in the long-term survival between ON-BH CABG and C-CABG.

Conclusions: With experienced and adept surgical team and mature ON-BH technology, ON-BH CABG may reduce the risk of postoperative death and complications in some patients. It might be an attractive alternative for high-risk patient populations.

Keywords: Coronary artery bypass graft (CABG); on-pump; beating heart; meta-analysis

Submitted Mar 31, 2021. Accepted for publication May 27, 2021.

doi: $10.21037 /$ jtd-21-568

View this article at: https://dx.doi.org/10.21037/jtd-21-568

\section{Introduction}

Conventional on-pump coronary artery bypass graft (C-CABG) was first introduced in the mid-1960s and developed rapidly as standard treatment for coronary revascularization. However, it may increase the risk of physiological disorders such as systemic inflammatory response, nervous system disorders, and renal failure due to the use of cardiopulmonary bypass (CPB), cardioplegic arrest and aortic cross-clamping (1-3). Offpump CABG (OPCAB) has been considered to be a 


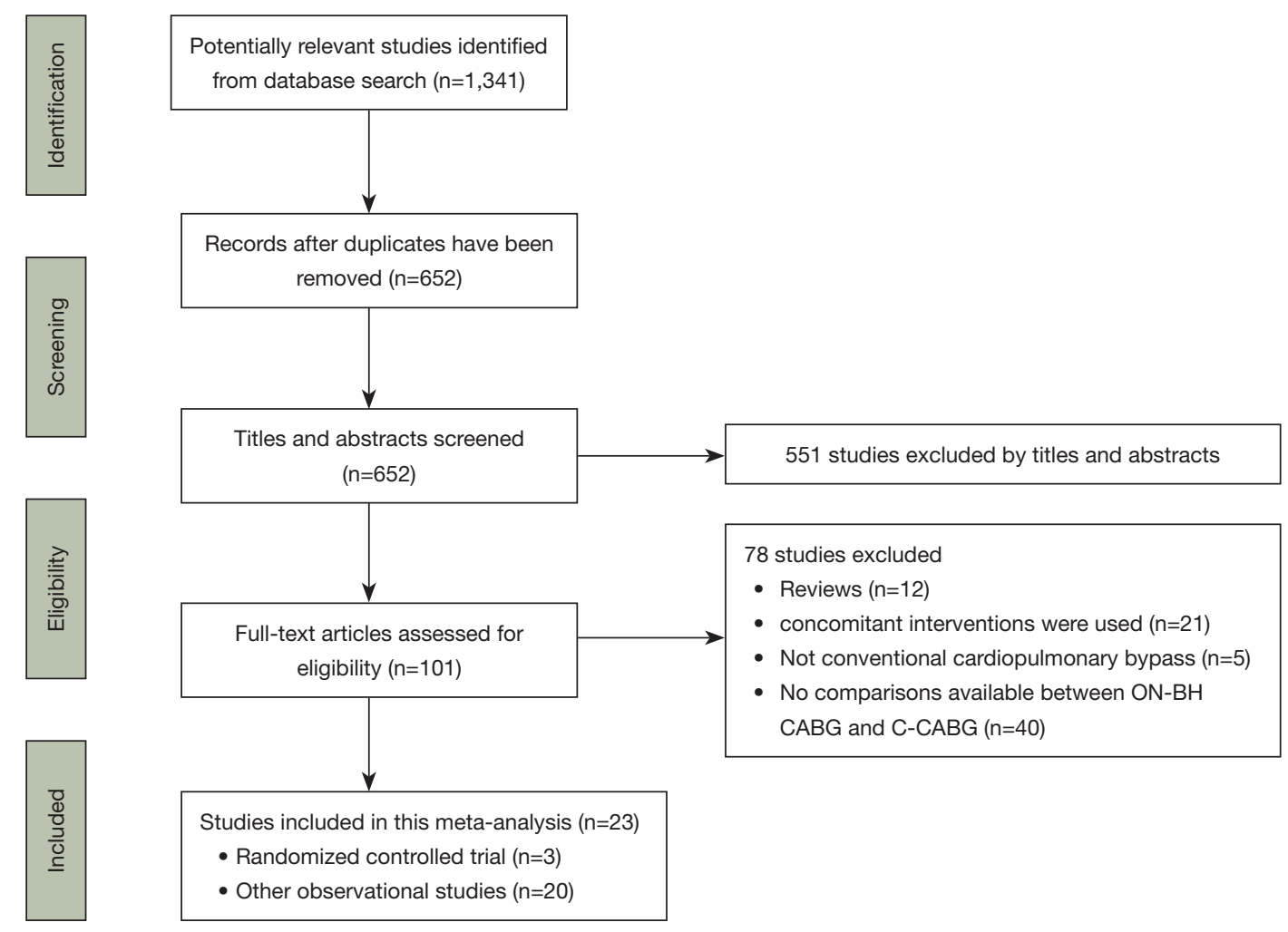

Figure 1 Flow diagram of search strategy. ON-BH CABG, on-pump beating heart coronary artery bypass graft; C-CABG, conventional onpump coronary artery bypass graft.

potentially ideal strategy to avoid serious complications of C-CABG, by obviating the use of CPB and cardioplegic arrest. However, there are studies increasingly reporting high incidence of incomplete revascularization and potentially inferior long-term survival with $\mathrm{OPCAB}$ (4-6). Therefore, a hybrid surgery method, on-pump beating heart coronary artery bypass graft (ON$\mathrm{BH}$ CABG) has been developed, which seems to be a promising technology for coronary artery revascularization. It allows performance of surgical operations while maintaining hemodynamic stability and providing adequate exposure to the target coronary artery, but without cardioplegic arrest and aortic cross-clamping (7). However, the clinical benefits of ON-BH CABG have not been clearly proven yet. The purpose of this study is to summarize the relevant published literature and conduct a systematic review, so as to evaluate whether ON-BH CABG has the potential to become an effective surgical method for coronary revascularization through short-term and longterm clinical outcomes compared with C-CABG.

We present the following article in accordance with the
PRISMA reporting checklist (available at https://dx.doi. org/10.21037/jtd-21-568) (8).

\section{Methods}

\section{Search strategy}

Literature searches were conducted through PubMed, EBSCO, Embase, Cochrane database and Web of Science up to 1 April, 2020. The following key terms were used either alone or in combination: "on pump", "cardiopulmonary bypass", "coronary artery bypass", "beating heart". The reference list of relevant articles and review were manually scrutinized to find additional studies. The included search was limited to human coronary artery bypass graft surgery research published in any country after 1990. A summary of our strategy is described in Figure 1.

\section{Eligibility criteria}

The inclusion criteria were as follows: (I) direct 
comparation of ON-BH CABG versus conventional onpump CABG; (II) provided at least one of the following major clinical outcomes: early mortality, long-term survival, myocardial infarction (MI), low output symptoms, incidence of incomplete revascularization, renal failure; (III) isolated CABG surgery.

The exclusion criteria were as follows: (I) concomitant interventions were used; (II) unconventional CPB was used; (III) the data provided was inaccurate and effective data extraction cannot be performed; (IV) repeated reporting of the same group of people research, in this case more credible and recently published data was selected. A study with a Newcastle-Ottawa Scale (NOS) score of 6 or higher was regarded as of high quality.

The study of patients who meet at least one of the following criteria is considered as a high-risk patient study (9): (I) unstable angina; (II) severe left main stenosis (more than 70 percent); (III) early post-acute MI or ongoing chest pain; (IV) post percutaneous coronary intervention (PCI) complication; (V) sever left ventricular dysfunction (left ventricular ejection fraction is less than 35 percent); (VI) severe renal failure; (VII) EuroSCORE score greater than 9.

Two independent reviewers (Chen Wang and Yefan Jiang) evaluated the research on the titles and abstracts of the searched articles based on our above selection and exclusion criteria which were summarized according to the PICOS (patient, intervention, comparator, outcome, and study design) approach, and then retrieved the full text of all possible eligible studies to determine the final selection. Any disagreements in the process will be resolved through discussion with the superior (Si Chen).

\section{Data collection}

The above two independent reviewers used standardized spreadsheets to extract data individually according to the first author, publication year, study location, study time span, study design, patient population, number of patients in groups, inclusion/exclusion criteria and outcome indicators.

\section{Research variables}

Our primary outcome was the early mortality rate in hospital and the long-term survival rate after surgery. Secondary outcomes was: (I) postoperative morbidity: MI, LOS, arrhythmia, renal dysfunction, hemodialysis (necessary for renal failure), reoperation due to bleeding, cerebrovascular disease, including stroke and transient ischemic attack, pulmonary complications, including lung infections and respiratory insufficiency; (II) perioperative outcomes: intra-aortic balloon pump (IABP) use; (III) graft outcomes: number of distal anastomoses and incidence of incomplete revascularization.

\section{Quality score and risk of bias analysis}

Two authors (Chen Wang and Yefan Jiang) used the Jadad composite scale (10) to assess the quality of RCTs and the modified Newcastle-Ottawa Quality Assessment Scale (11) to rate the quality of observational studies, then gave an evaluation score for each study. High-quality studies were defined as those with a Jadad score of 2 or higher (maximum, 5), or a modified Newcastle-Ottawa score of 5 or higher (maximum, 9). The risk of bias of the included literature was assessed according to Cochrane guidelines (12).

\section{Statistical analysis}

The meta-analysis uses a weighted fixed effects model to analyze the data. For our primary outcomes, the odds ratio (OR) and the logarithm of hazard ratio (HR) with $95 \%$ confidence interval (CI) were used as summary statistics to calculate survival differences. For secondary outcomes, categorical variables were evaluated using OR. The point estimate of the OR was considered statistically significant if $\mathrm{P}$ was less than 0.05 and the $95 \% \mathrm{CI}$ did not include the value 1 . Continuous variables are evaluated using weighted mean difference (WMD). The point estimate of WMD was considered to be statistically significant if $\mathrm{P}$ was less than 0.05 and the $95 \% \mathrm{CI}$ did not include 0 .

\section{Heterogeneity}

If statistically significant heterogeneity is found in the included studies, random effects models can also be used for pooled analysis, and subgroup analysis and sensitivity analysis can be performed to discover the source of heterogeneity. Cochran's Q test was used to test the heterogeneity of the included studies. The significance level was set to $\mathrm{P}$ value $<0.10$, and was quantified by using the $\mathrm{I}^{2}$ statistic, where value of $50 \%$ or greater indicated substantial heterogeneity. Sensitivity analyses were performed by omitting each study in sequence. Publication bias was assessed by visual inspection of funnel plots.

This meta-analysis conducted not only a systematic analysis of all entered documents that meet the standards to 
Table 1 Synopsis of including studies

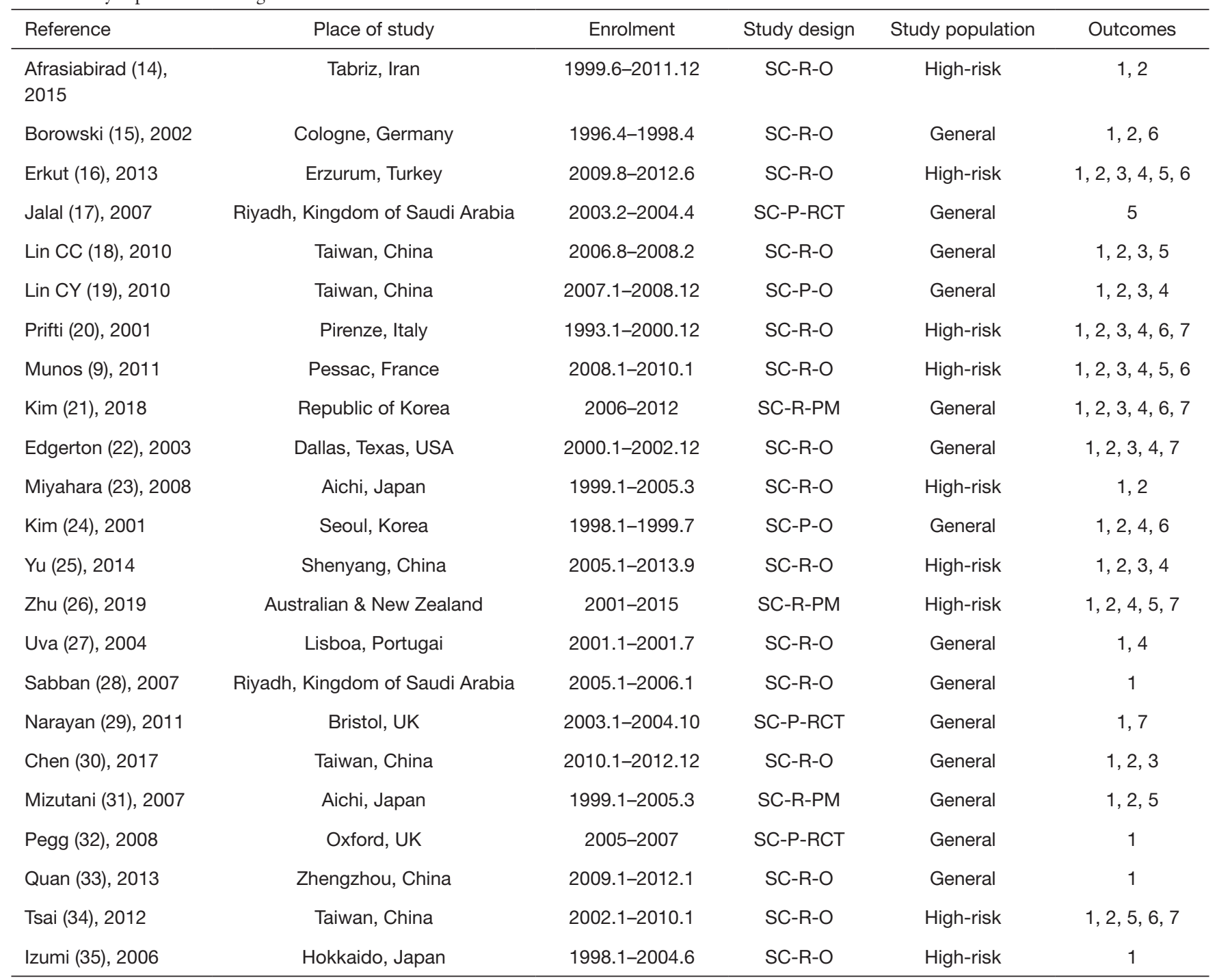

O, observational; P, prospective; PM, propensity matched; R, randomized; RCT, randomized controlled trial; SC, single center; R-O, retrospective observational; P-O, prospective-observational; 1 , early mortality; 2, renal failure; 3 , dialysis (renal failure); 4, myocardial infarction; 5 , incidence of incomplete revascularization; 6 , low cardiac output syndrome; 7 , long-term survival.

make an overall comparison between ON-BH CABG and C-CABG, but also a systematic analysis of the literature on high-risk patients to evaluate the clinical effects of $\mathrm{ON}-\mathrm{BH}$ CABG. The meta-analysis was conducted in accordance with the PRISMA (Preferred Reporting Project for Systematic Reviews and Meta-analysis) guidelines, following Cochrane recommendations and using Review Manager 5.3 software.

\section{Results}

Our research identified 24 studies $(9,13-35)$ according to our inclusion and exclusion criteria initially. However, one observational study (13) was excluded because its Newcastle-Ottawa score was below 4. Finally, 23 studies (9,14-35) were included in our research incorporating a total of 6,862 patients $(1,847 \mathrm{ON}-\mathrm{BH}$ CABG; 5,015 $\mathrm{C}-\mathrm{CABG})$. The main characteristics of the included studies are listed in Table 1 and the demographic data characteristics are listed in Table 2. Three studies $(17,29,32)$ were randomized controlled trials, $2(19,24)$ were prospectively non-randomized controlled studies, and 18 (9,14-16,18,20$23,25-28,30,31,33-35)$ were retrospective observational 


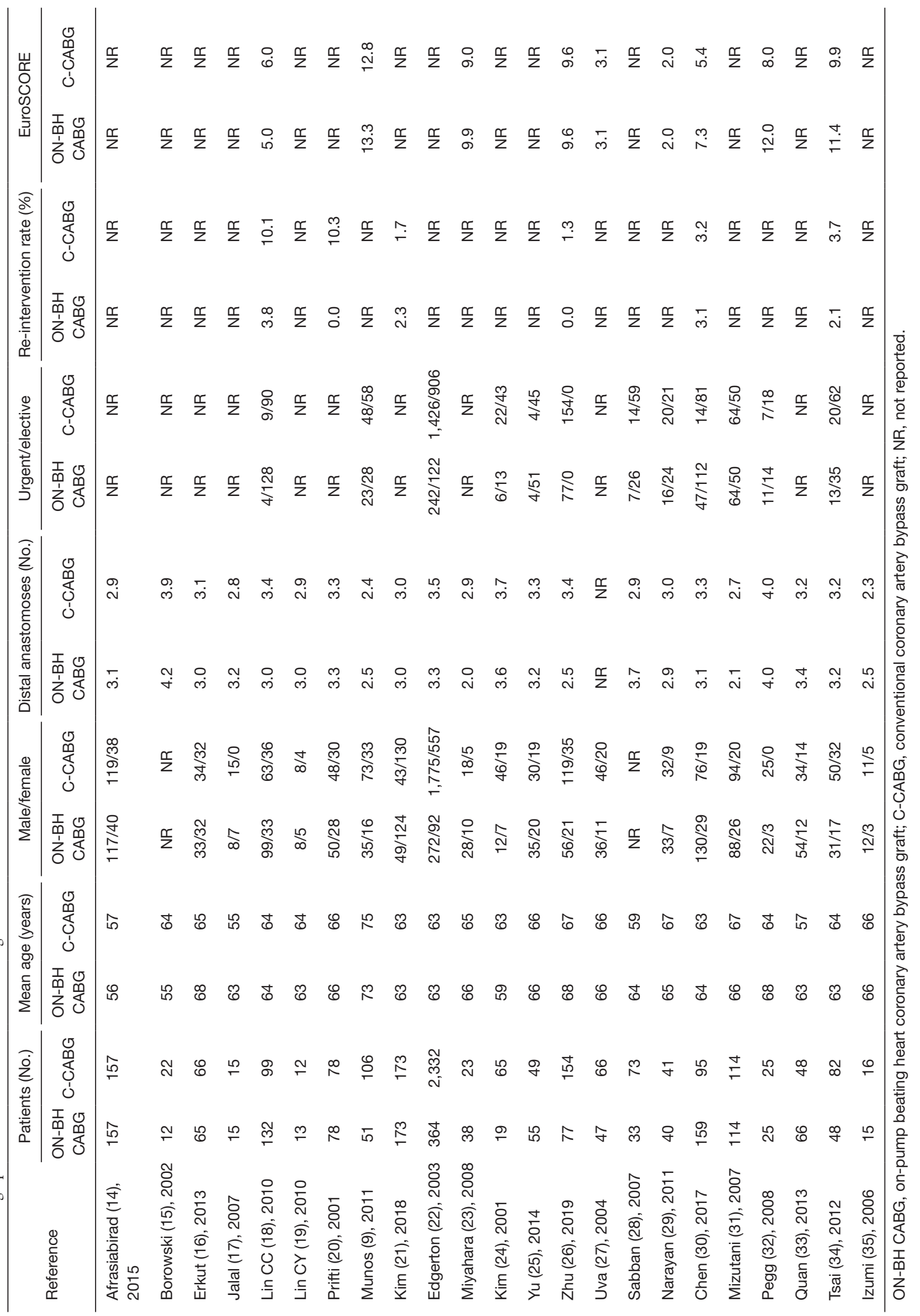




\begin{tabular}{|c|c|c|c|c|c|}
\hline \multirow[b]{2}{*}{ Study or Subgroup } & \multicolumn{2}{|c|}{ C-CABG } & \multicolumn{2}{|c|}{ ON-BH CABG } & \multirow[b]{2}{*}{ Weight } \\
\hline & Events & Total & Events & Total & \\
\hline Abbas Afrasiabirad 2013 & 14 & 157 & 5 & 157 & $7.5 \%$ \\
\hline Andreas Borowski 2000 & 3 & 22 & 2 & 12 & $2.2 \%$ \\
\hline Bilgehan Erkut 2013 & 14 & 66 & 2 & 65 & $3.5 \%$ \\
\hline Chien-Chao Lin 2010 & 11 & 99 & 10 & 132 & $10.1 \%$ \\
\hline Chih-Yuan Lin 2010 & 0 & 12 & 0 & 13 & \\
\hline Edvin Prifti 2001 & 9 & 78 & 6 & 78 & $7.0 \%$ \\
\hline Emmanuel Munos 2011 & 6 & 106 & 1 & 51 & $1.8 \%$ \\
\hline Ho Jin Kim 2018 & 0 & 173 & 2 & 173 & $0.9 \%$ \\
\hline James R. Edgerton 2003 & 82 & 2332 & 16 & 364 & $27.3 \%$ \\
\hline Ken Miyahara 2008 & 5 & 23 & 1 & 38 & $1.7 \%$ \\
\hline Ki-Bong Kim 2001 & 2 & 65 & 0 & 19 & $0.9 \%$ \\
\hline Lei Yu 2014 & 14 & 49 & 3 & 55 & $4.7 \%$ \\
\hline Michael Z.L. Zhu 2019 & 16 & 154 & 9 & 77 & $10.9 \%$ \\
\hline Miguel Sousa Uva 2003 & 1 & 66 & 2 & 47 & $1.4 \%$ \\
\hline Mostafa A. Sabban 2007 & 3 & 73 & 2 & 33 & $2.4 \%$ \\
\hline Pradeep Narayan 2011 & 0 & 41 & 0 & 40 & \\
\hline Shao-Wei Chen 2017 & 4 & 95 & 10 & 159 & $5.8 \%$ \\
\hline Shinichi Mizutani 2007 & 11 & 114 & 3 & 114 & $4.8 \%$ \\
\hline Tammy J. Pegg 2008 & 0 & 25 & 1 & 25 & $0.8 \%$ \\
\hline Xiaoqiang Quan 2013 & 4 & 48 & 0 & 66 & $0.9 \%$ \\
\hline Yi-Ting Tsai 2012 & 7 & 82 & 2 & 48 & $3.1 \%$ \\
\hline Yuichi Izumi 2006 & 5 & 16 & 2 & 15 & $2.5 \%$ \\
\hline Total $(95 \% \mathrm{Cl})$ & & 3896 & & 1781 & $100.0 \%$ \\
\hline Total events & 211 & & 79 & & \\
\hline
\end{tabular}
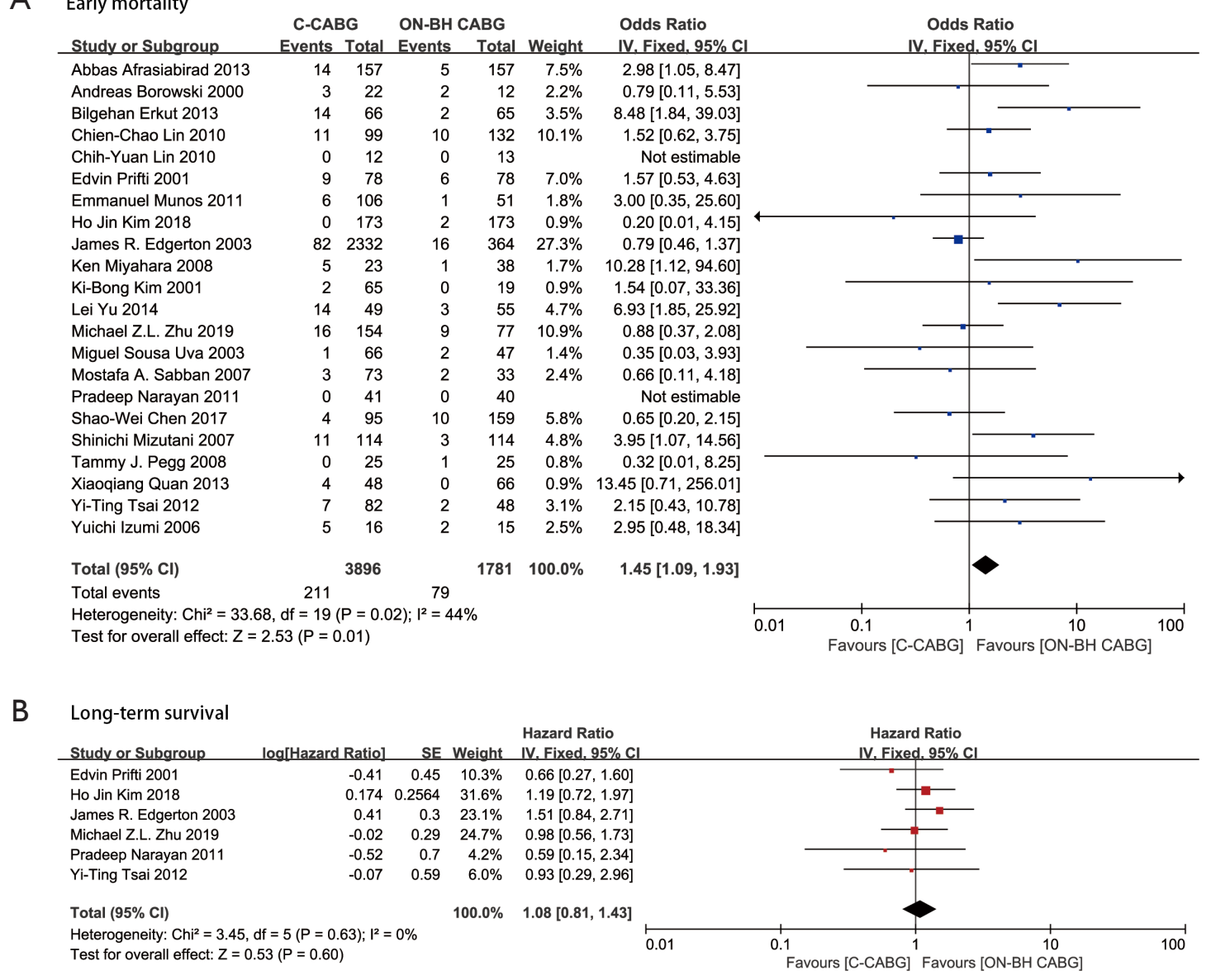

Figure 2 Forest plots of outcomes on ON-BH CABG and C-CABG groups. (A) Early mortality, (B) long-term survival. CI, confidence interval; IV, inverse variance; SE, standard error; ON-BH CABG, on-pump beating heart coronary artery bypass graft; C-CABG, conventional on-pump coronary artery bypass graft.

studies, of which three studies $(21,26,31)$ were propensity score matching for risk adjustment. A total of nine studies $(9,14,16,20,23,25,26,34,35)$ focused on high-risk patients.

The present part is structured in the following sections: (I) primary outcome (early mortality and long-term survival); (II) secondary outcome (major postoperative complication); (III) high-risk patients.

\section{Primary outcome}

The forest plot results of primary outcomes were shown in Figure 2. Early death was defined as death occurring within 30 days after surgery or as an in-hospital death at any time. A total of 22 studies (9,14-16,18-35) reported data related to early ( $<30$ days) mortality. The early ( $<30$ days) mortality was higher in conventional CABG when compared with OP-BH CABG in the fixed-effects model (OR, $1.45 ; 95 \% \mathrm{CI}, 1.09$ to $1.93 ; \mathrm{P}=0.01)$, without significant heterogeneity $\left(\mathrm{I}^{2}=44 \%\right)$. Exclusion of each study in sequence did not influence the overall results (Figure $2 A$ ). It was worth noting that the retrospective study by Edgerton et al. (22) was the only study that accounts for more than $20 \%$ of the population and similar result can be obtained after removing this study. Six studies (20-22,26,29,34) providing details related to the long-term survival were included in the long-term survival analysis. No difference was found in long-term survival between $\mathrm{BH}-\mathrm{ONCAB}$ and $\mathrm{C}-\mathrm{ONCAB}$ in the fixed-effects model (HR, 1.08; 95\% CI, 0.81 to 1.43 ), with no heterogeneity $\left(\mathrm{I}^{2}=0 \%\right)$ (Figure $\left.2 B\right)$. 


\section{Secondary outcome}

The forest plot results of secondary outcomes were shown in Figure 3. Ten studies $(9,16,19-22,24-27)$ provided data on postoperative MI. C-CABG was with a significantly higher risk compared with OP-BH CABG and is statistically different (OR, 2.60; 95\% CI, 1.41 to 4.78 ; $\mathrm{P}=0.002$ ). No significant heterogeneity was observed in included studies $\left(\mathrm{P}=0.60, \mathrm{I}^{2}=0 \%\right)$ (Figure $\left.3 C\right)$.

There were 7 studies $(9,15,16,20,21,24,34)$ reporting the occurrence of postoperative LOS, and the risk in C-CABG was significantly higher than that in ON-BH CABG in the fixed-effects model (OR, 2.56; 95\% CI, 1.55 to 4.23; $\mathrm{P}<0.001)$. No significant heterogeneity was observed in included studies $\left(\mathrm{P}=0.35, \mathrm{I}^{2}=10 \%\right)$ (Figure $\left.3 D\right)$.

There were 16 studies (9,14-16,18-26,30,31,34) reporting the occurrence of renal failure. However, one study (22) was excluded because it significantly increased the heterogeneity due to more patients with renal failure before surgery in the ON-BH CABG group than in the C-CABG group with statistical difference. When it was removed, the $\mathrm{I}^{2}$ value of the index of heterogeneity dropped from $70 \%$ to $27 \%$ (Figure 4). The risk of postoperative renal failure in $\mathrm{C}-\mathrm{CABG}$ is significantly higher than that of OP-BH CABG with a statistical difference (OR, 1.84; $95 \%$ CI, 1.38 to 2.44; $\mathrm{P}<0.01$ ) (Figure 3A). However, in the study of data provided by 7 studies $(9,16,18,19,22,25,30)$ on postoperative patients requiring hemodialysis due to renal failure, it was found that there was no significant difference in hemodialysis caused by the two surgical methods (OR, 1.25; 95\% CI, 0.74 to $2.12 ; \mathrm{P}=0.41$ ) (Figure $3 B$ ).

Five studies $(9,16,18,26,34)$ focused on the incidence of incomplete revascularization and no difference was found in the incidence of incomplete revascularization between $\mathrm{ON}$ BH CABG and C-CABG (OR, 0.65; 95\% CI, 0.40 to 1.05 ; $\mathrm{P}=0.08)$, without significant heterogeneity $\left(\mathrm{P}=0.79, \mathrm{I}^{2}=0 \%\right)$ in the fixed effects model (Figure 3E).

\section{High-risk patients}

Data for high-risk patients were available for 9 studies $(9,14,16,20,23,25,26,34,35)$. We further explored the clinical outcomes of those two surgical methods in high-risk patients. The forest plot results of outcomes of high-risk patients were shown in Figures 5 and 6. The early mortality rate of high-risk patients in C-CABG was significantly higher than that of ON-BH CABG in the fixed-effect model (OR, 2.37; 95\% CI, 1.53 to $3.68 ; \mathrm{P}<0.01)$ and there was no significant heterogeneity $\left(\mathrm{P}=0.14 ; \mathrm{I}^{2}=34 \%\right)$ (Figure $\left.5 A\right)$. However, no significant difference existed in the long-term survival rate between those two surgical methods (HR, 1.08; 95\% CI, 0.70 to $1.69 ; \mathrm{P}=0.72$ ) (Figure 5B). Compared with C-CABG, patients of ON-BP CABG had significantly lower incidence of postoperative $\mathrm{MI}(\mathrm{OR}, 3.68 ; 95 \% \mathrm{CI}$, 1.72 to $7.87 ; \mathrm{P}<0.01$ ) (Figure 5C), LOS (OR, 3.18; 95\% CI, 1.86 to $5.44 ; \mathrm{P}<0.01$ ) (Figure $5 \mathrm{D})$, renal failure $(\mathrm{OR}, 2.50$; 95\% CI, 1.67 to $3.75 ; \mathrm{P}<0.01)$ and hemodialysis $(\mathrm{OR}, 4.00$; $95 \% \mathrm{CI}, 1.93$ to 8.28 ; $\mathrm{P}<0.01$ ), IABP usage (OR, 2.03; $95 \%$ CI, 1.44 to $2.84 ; \mathrm{P}<0.01$ ), pulmonary complication (OR, $2.11 ; 95 \% \mathrm{CI}, 1.13$ to $3.94 ; \mathrm{P}=0.02$ ) (Figure $6 A, B, D, F)$. Except for IABP use, none of the other results showed obvious heterogeneity. There was no significant difference in arrhythmia (OR, 1.10; 95\% CI, 0.68 to $1.78 ; \mathrm{P}=0.69$ ), cerebrovascular disease (OR, 2.17; 95\% CI, 0.94 to 5.01; $\mathrm{P}=0.07)$, the incidence of incomplete revascularization (OR, $0.77 ; 95 \% \mathrm{CI}, 0.41$ to $1.43 ; \mathrm{P}=0.41$ ) and reoperation due to bleeding (OR, 1.64; 95\% CI, 0.79 to $3.40 ; \mathrm{P}=0.19$ ) in high-risk patients between C-CABG and ON-BH CABG (Figure 6C,E,G,H).

\section{Discussion}

The results demonstrated that ON-BH CABG had a lower early morbidity, lower mortality, and similar longterm survival compared with C-CABG. The incidences of MI, low output syndrome (LOS), and renal failure of ON$\mathrm{BH}$ CABG are lower significantly than that of C-CABG. In high-risk patients, ON-BH CABG had obvious advantages on reducing early mortality and the incidence of complications after coronary artery bypass grafting surgery but did not improve long-term survival. Those results indicate the promising clinical potential of ON-BH CABG.

Our meta-analysis shows that ON-BH CABG has lower incidence of postoperative MI and cardiac LOS. This result may be explained by the difference in technology of these two methods. Both ON-BH CABG and C-CABG use the support of $\mathrm{CPB}$ during the operation to enable mechanical stability. The difference is that ON-BH CABG avoids aortic cross-clamping and cardioplegic arrest (36). The avoidance of cross-clamping of the aorta in severe atherosclerosis could minimize the risk of embolization from atherosclerotic debris (37). The avoidance of cardioplegic arrest could preserve native coronary blood flow, prevent overall myocardial ischemia and ischemiareperfusion injury $(23,38)$, thus preserve more myocardial function and reduce the occurrence of postoperative MI 


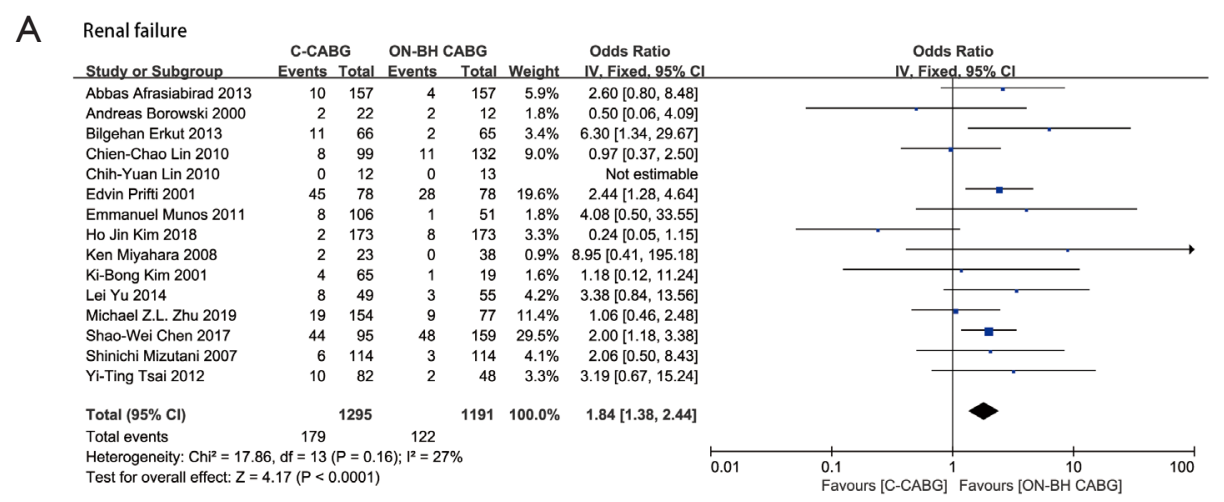

\section{B}

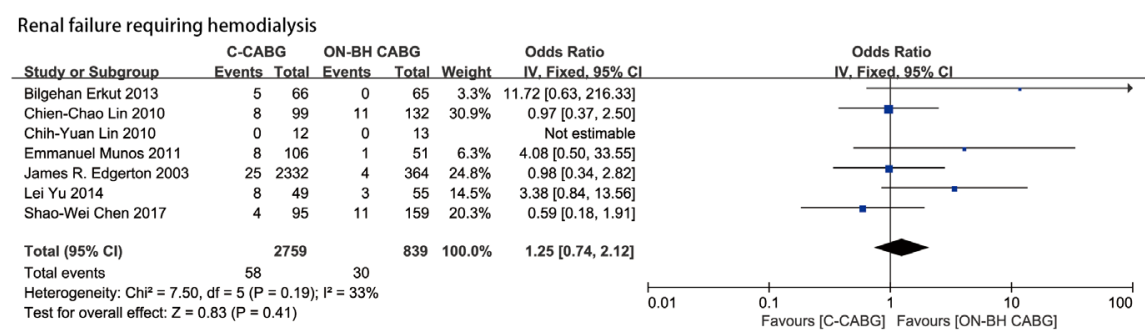

C

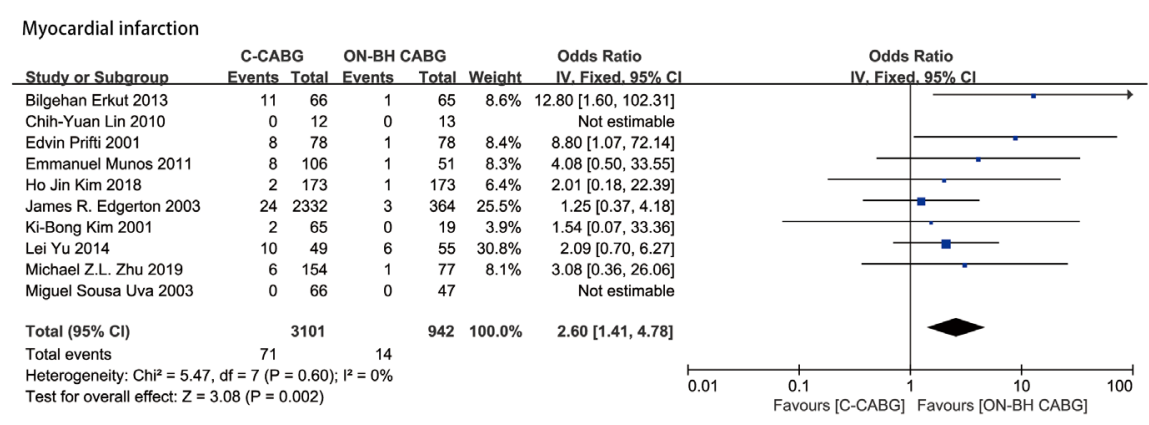

D low output syndrome

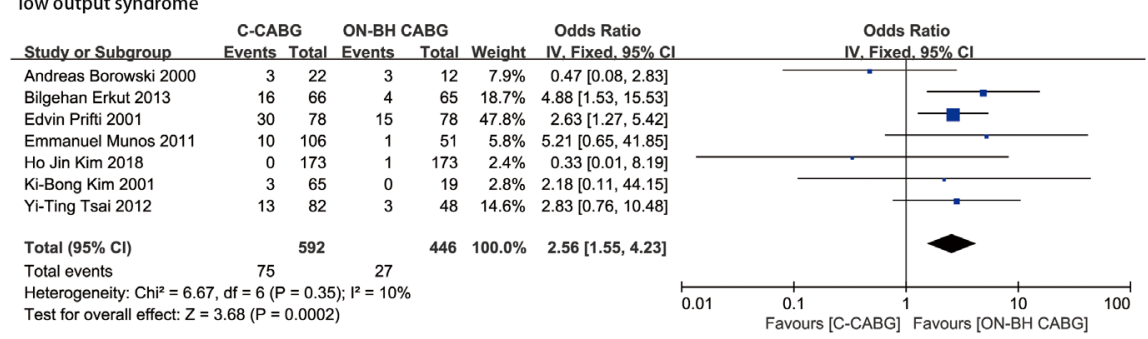

E Incidence of incomplete revascularization

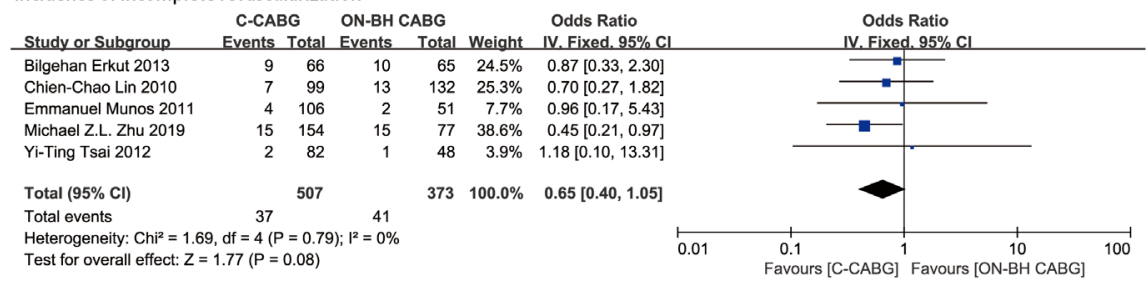

Figure 3 Forest plots outcomes on ON-BH CABG and C-CABG groups. (A) Renal failure, (B) renal failure requiring hemodialysis, (C) myocardial infarction, (D) low output syndrome, (E) incomplete revascularization. CI, confidence interval; IV, inverse variance; ON-BH CABG, on-pump beating heart coronary artery bypass graft; C-CABG, conventional on-pump coronary artery bypass graft. 
A

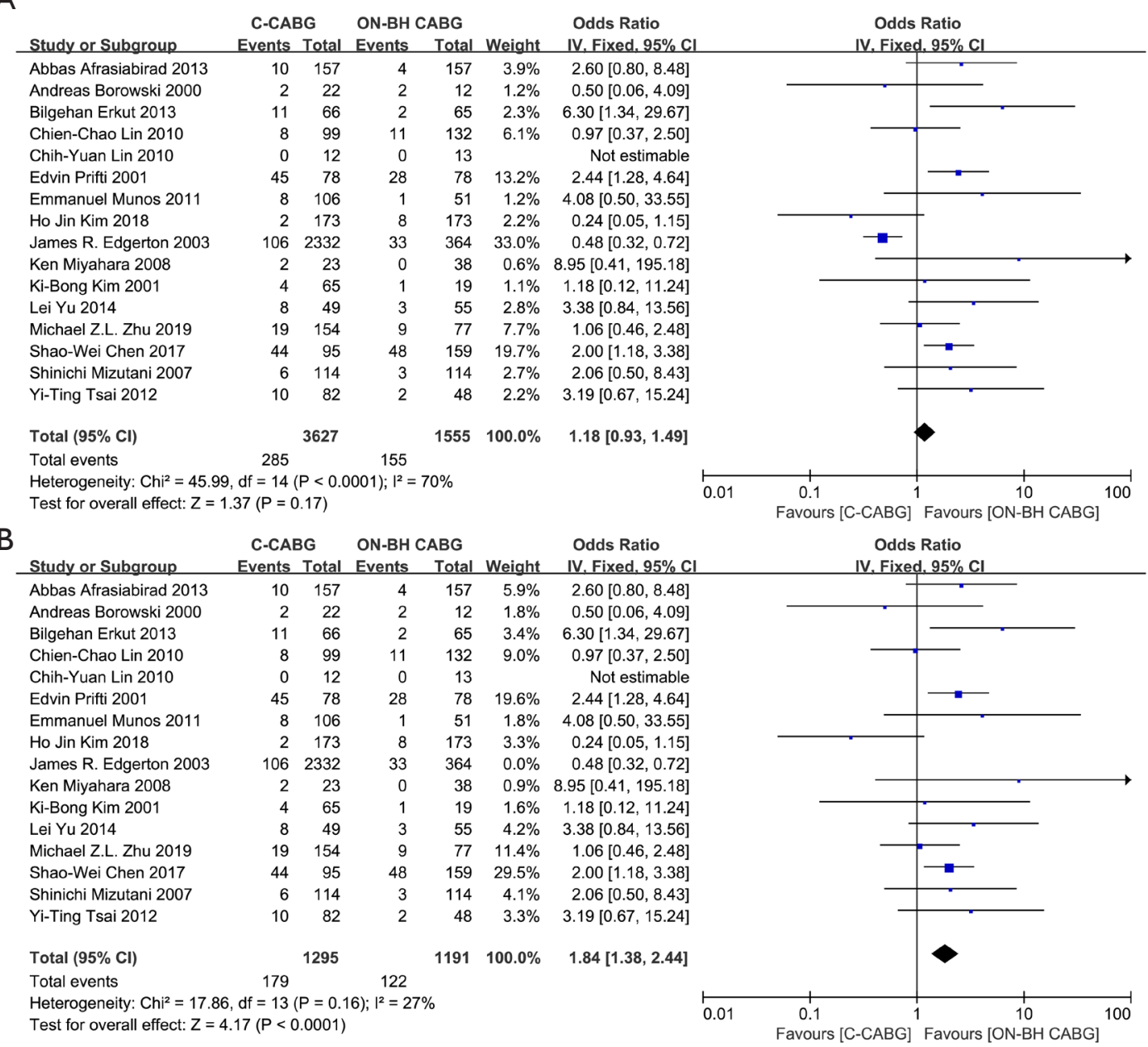

Figure 4 Sensitivity analysis of postoperative renal failure. (A) Forest plot with the study of Edgerton et al., (B) Forest plot without the study of Edgerton et al.

and LOS. It has been reported that while the functional myocardium was lost in the infarcted area, the remaining non-infarcted myocardium would undergo adaptive response rapidly to compensate for the infarcted area after acute MI (19). For example, adenosine triphosphate, phosphocreatine and glycogen were depleted, while lactate and oxygen consumption were increased (39). Consequently, if the non-infarcted myocardium is further damaged by ischemia and reperfusion due to cardioplegic arrest and aortic cross-clamping, its metabolic state may be even more impaired, thus leading to profound damage to myocardial function (39-41). The effect of myocardial protection of ON-BH CABG had also been confirmed in the studies of Izumi (35), Borowski (15) and Miyahara (23). Despite all these supporting evidence, the opposite research results also exist. Pegg et al. (32) reported that the incidence of new irreversible myocardial injury was significantly higher in $\mathrm{ON}-\mathrm{BH}$ CABG and the technique was related with poorer early and late cardiac remodeling. Ueki et al. (42) found that the opposite result might be explained by the relatively low mean arterial pressure $(50-60 \mathrm{mmHg}$ ) during $\mathrm{ON}$ BH CABG in the series of Pegg because another similar study (29) reported no significant difference in myocardial injury with higher mean arterial pressures $(70-80 \mathrm{mmHg})$. Thus, they suggested that maintaining a relatively high mean arterial pressure during ON-BH CABG is essential to improve myocardial perfusion.

At present, there is no meta-analysis that compares the incidence of renal failure and hemodialysis between $\mathrm{ON}$ BH CABG and C-CABG at the same time. Our analysis 
A

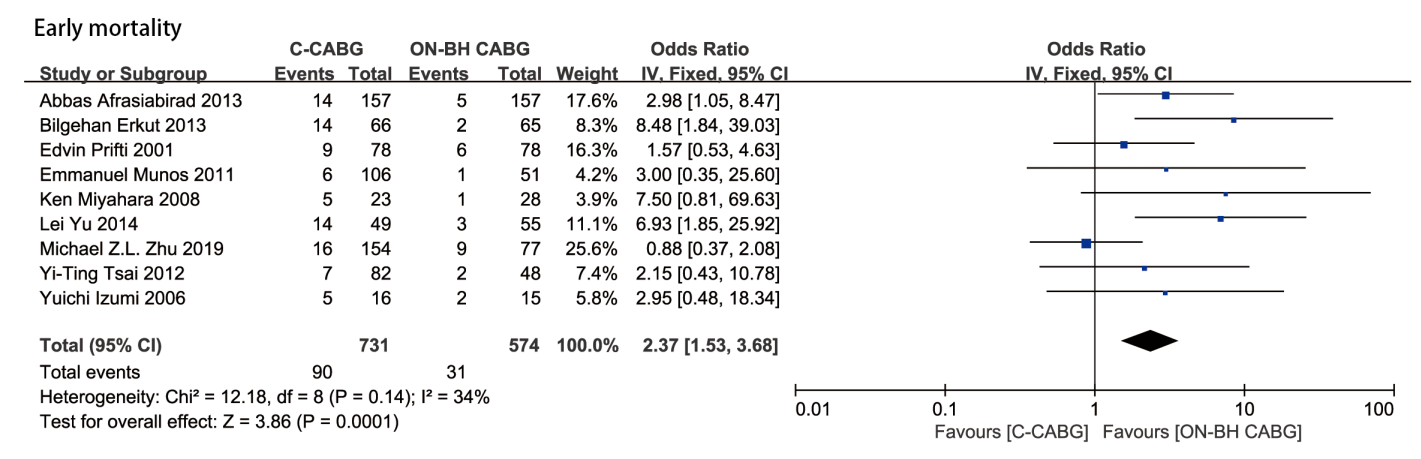

B
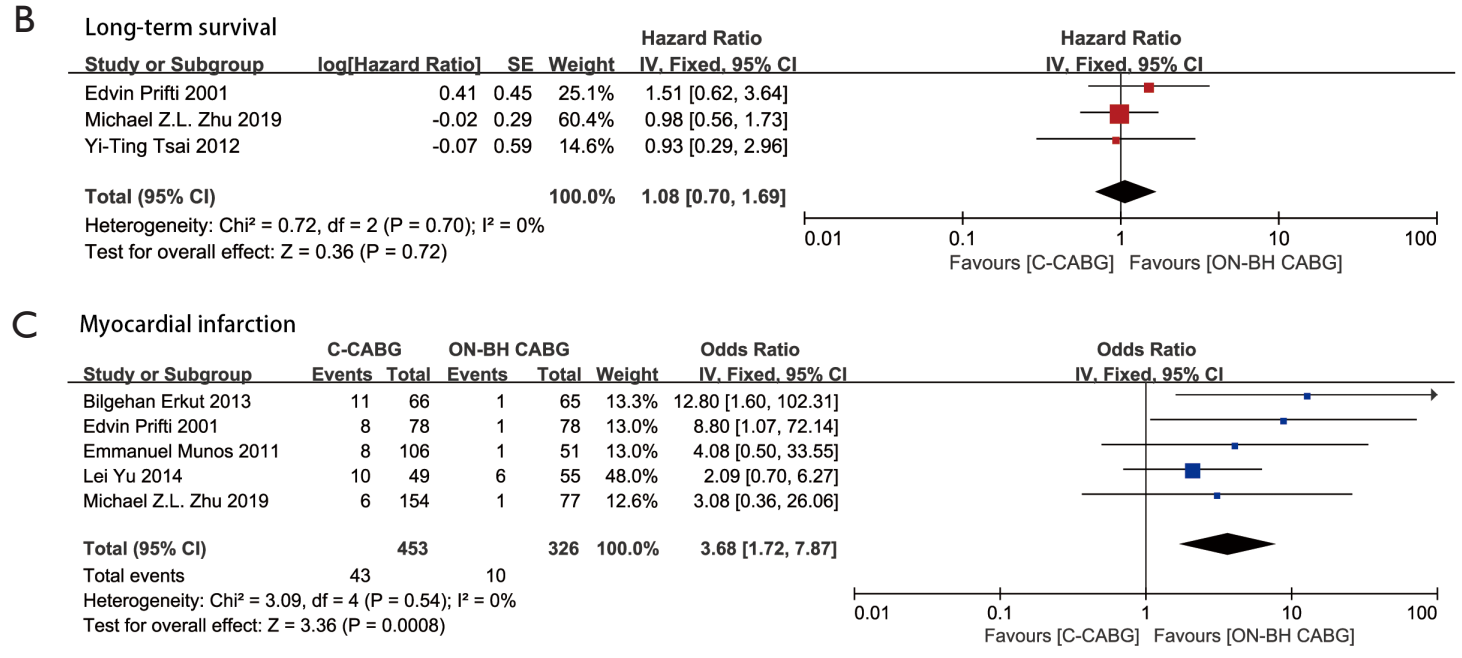

D Low output syndrome

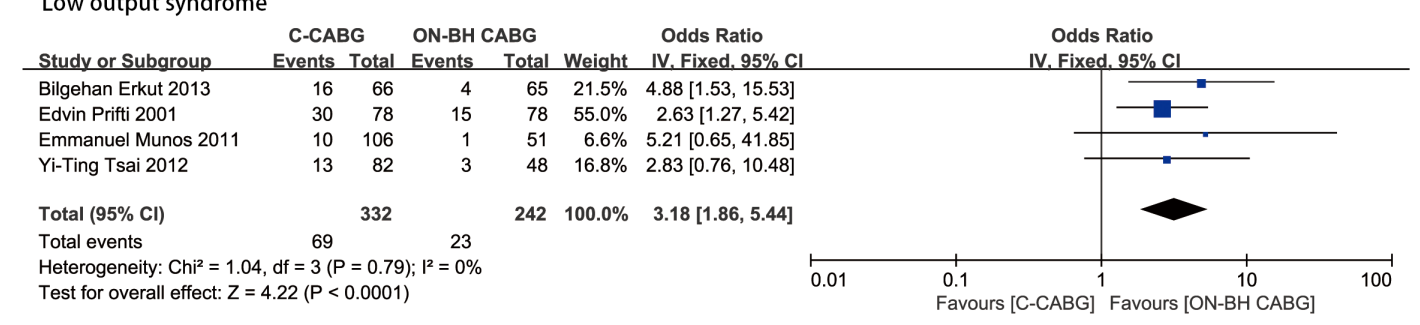

Figure 5 Forest plots of outcomes on ON-BH CABG and C-CABG groups in high-risk patients. (A) Early mortality, (B) long-term survival, (C) myocardial infarction, (D) low output syndrome. CI, confidence interval; IV, inverse variance; SE, standard error; ON-BH CABG, onpump beating heart coronary artery bypass graft; C-CABG, conventional on-pump coronary artery bypass graft.

demonstrated the incidence of renal failure after $\mathrm{ON}-\mathrm{BH}$ CABG was significantly lower than that of C-CABG, which was more pronounced in high-risk patients. This result suggested that $\mathrm{ON}-\mathrm{BH}$ technology somehow protected the renal function of patients. The protective effect might be related to the avoidance of systemic hypothermia and visceral blood flow hypoperfusion, and the reduction of CPB time during ON-BH CABG surgery (43-45). Recovery from myocardial stunning and rewarming on $\mathrm{CPB}$ have been proven to be risk factors for acute kidney injury (AKI) (44). In addition, the lower incidence of MI and LOS after ON-BH CABG protects the kidney from damage due to insufficient perfusion caused by unstable hemodynamics. Previously, some scholars proposed that OP-BH technology reduced the damage on important organs during the operation by avoiding the release of inflammatory factors related to ischemia-reperfusion injury caused by cardiac arrest. Rothenburger et al. (46) proved that both cardiac 
A

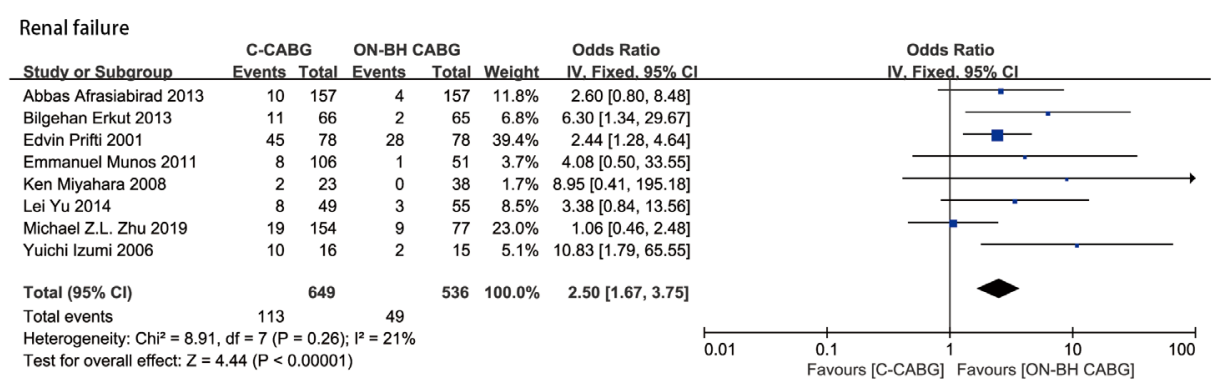

B

Renai failure requiring hemodialysis

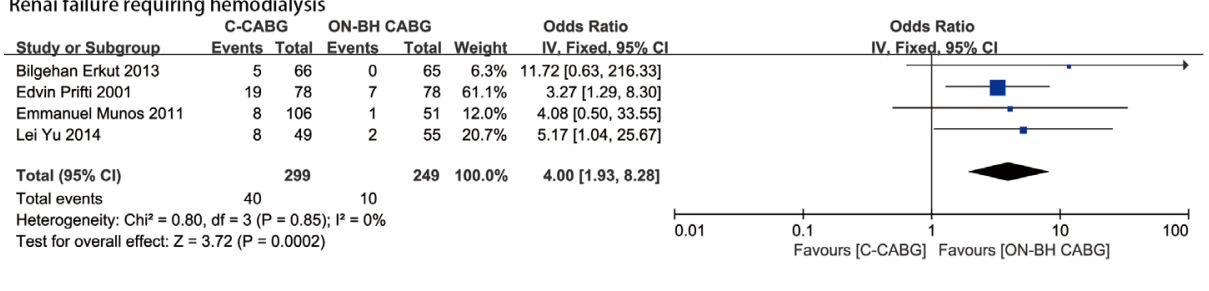

C

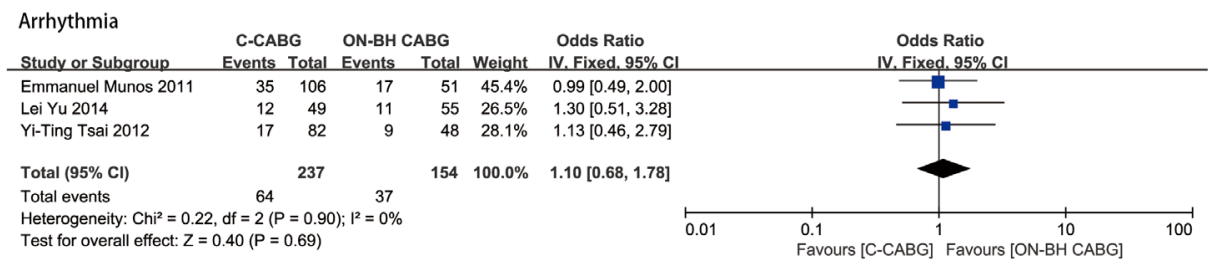

D IABP use

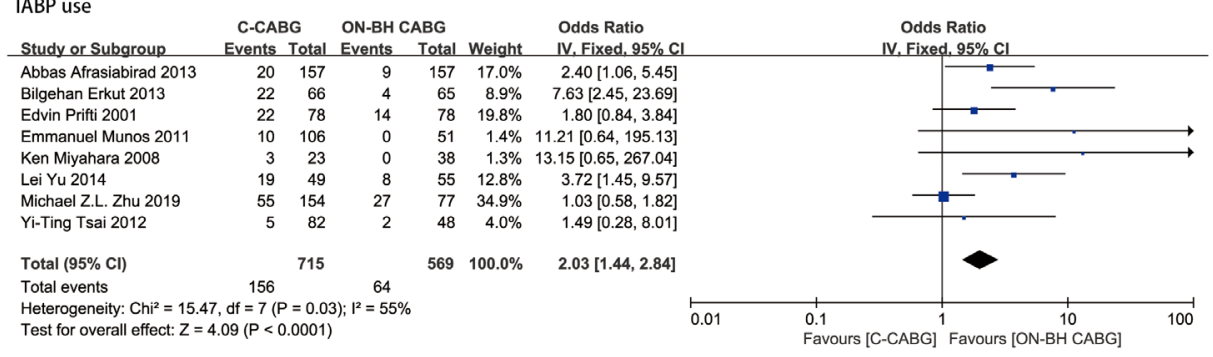

$E$

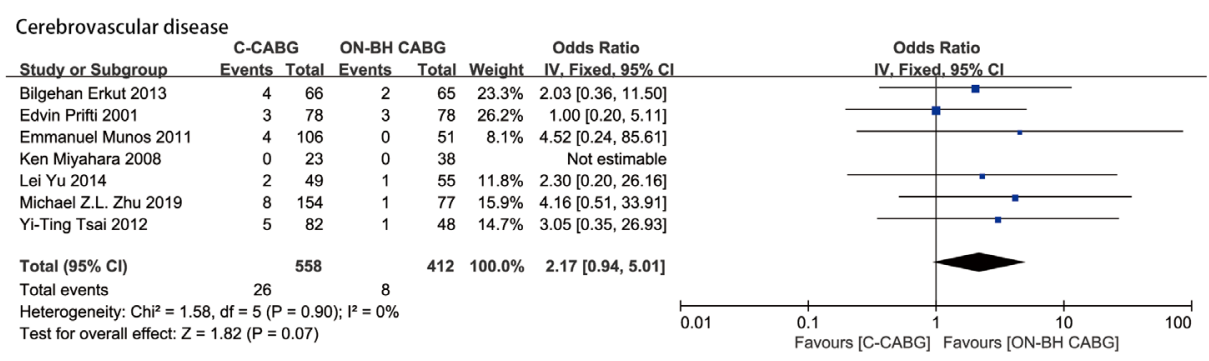

F Pulmonary complication

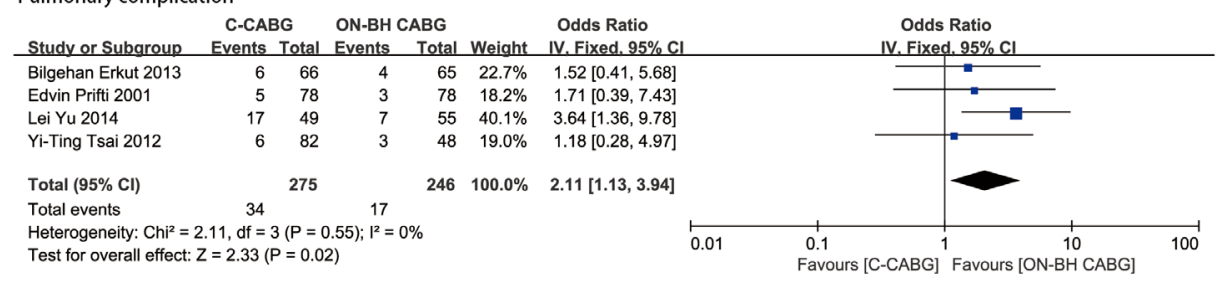

(c) Journal of Thoracic Disease. All rights reserved. 

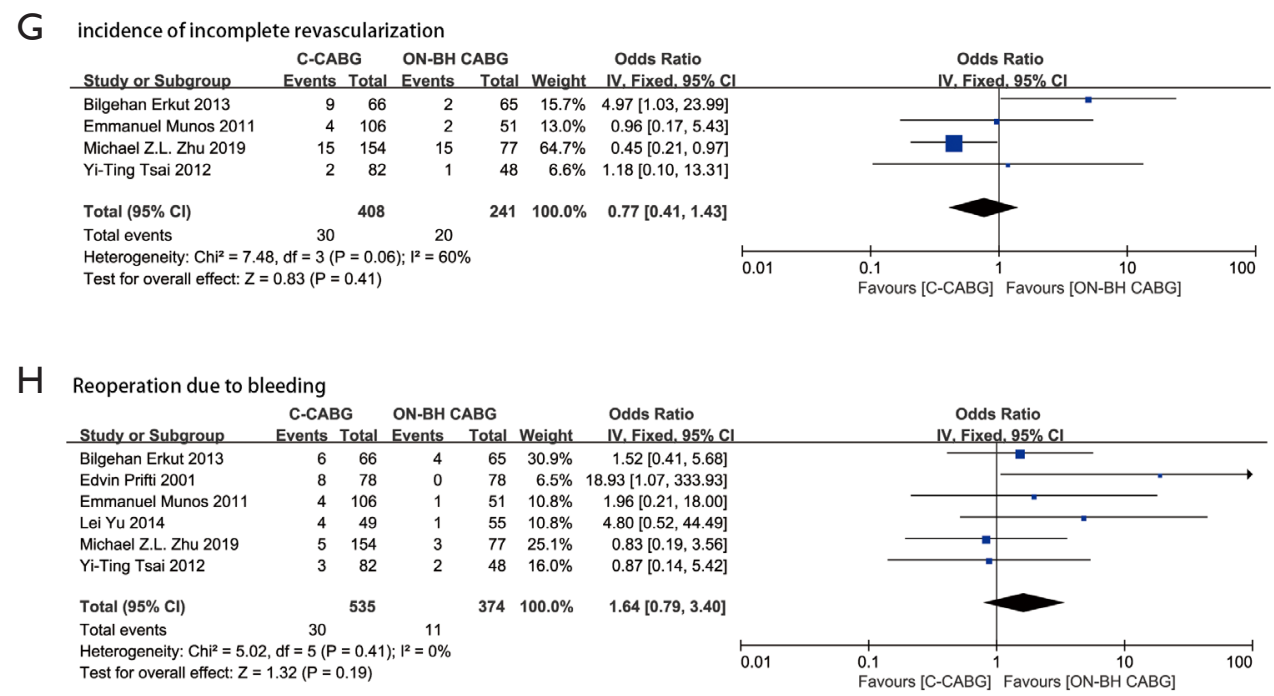

Figure 6 Forest plots of outcomes on ON-BH CABG and C-CABG groups in high-risk patients. (A) Renal failure, (B) renal failure requiring hemodialysis, (C) arrhythmia, (D) IABP use, (E) cerebrovascular disease, (F) pulmonary complication, (G) incomplete revascularization, $(\mathrm{H})$ reoperation due to bleeding. $\mathrm{CI}$, confidence interval; IV, inverse variance; ON-BH CABG, on-pump beating heart coronary artery bypass graft; C-CABG, conventional on-pump coronary artery bypass graft.

surgery and CPB can induce inflammation and antiinflammatory immune responses, and the imbalance between inflammation and anti-inflammatory mediators was essential for postoperative systemic inflammatory response syndrome. However, Narayan et al. (29) monitored the interleukins (IL-6, IL-8 and IL-10) in the ON-BH CABG and C-CABG group continuously after surgery and found that there was no statistical difference between the two groups. This may indicate that the protection of kidney in ON-BH CABG is not mainly achieved by reducing inflammation. The results of our analysis also showed that there was no significant difference in hemodialysis after these two surgical procedures in the overall comparison. By contrast, in the comparison of high-risk patients, the number of patients requiring hemodialysis after C-CABG was significantly higher than that of ON-BH CABG. This indicated that high-risk patients, especially those with abnormal renal function before surgery, could benefit more from ON-BH CABG surgery.

Whether ON-BH CABG could achieve complete cardiac revascularization and ensure the long-term survival is a question worthy of most attention. In recent years, offpump CABG has been questioned due to reports of high incidence of incomplete revascularization and less favorable long-term survival $(47,48)$. Our meta-analysis showed that the ON-BH CABG and C-CABG groups had no significant differences in the incidence of incomplete revascularization and long-term survival, and no significant heterogeneity was found. ON-BH CABG benefits from the support of $\mathrm{CPB}$, which could provide more stable hemodynamics and increase the tolerance of the heart to movement. This allows better exposure of target arteries and operation space for operators to achieve complete revascularization during operation. Edgerton et al. (22) report that ON-BH CABG can ensure complete revascularization of high risk patients with cardiogenic shock, requiring resuscitation, recent MI, a low ejection fraction, or unstable arrhythmias. Takagi et al. (49) showed that adequate and guaranteed complete revascularization is closely related to the long-term survival. To the opposite, a previous meta-analysis that included 14 literatures reported a significantly greater risk of incomplete revascularization in ON-BH CABG compared with C-CABG (42). However, that meta-analysis showed significant heterogeneity among studies included and there was no comprehensive analysis of the heterogeneity to determine its source. Therefore, our analysis results are supposed to be more reasonable and reliable.

Due to the high early mortality and morbidity in highrisk patients undergoing C-CABG surgery, a part of surgeons chose off-pump CABG as an alternative method for coronary revascularization in these cases. However, beside the concerns related to potentially inferior long- 
term survival and the high incidence of incomplete revascularization, hemodynamic instability might require emergent conversion to conventional on-pump CABG, especially in case of severe coronary disease, increasing the risk of operation enormously $(22,48,50)$. A survey in Japan showed that $4.5 \%$ of emergency isolated CABG were converted from off-pumps to on-pump in 2004, and the hospital mortality for this part of patients even reached $23.8 \%$ (51). This meta-analysis has shown that ON-BH CABG has great advantages over reducing early mortality and the occurrence of postoperative MI, LOS, renal failure and pulmonary complications in high-risk patients compared with C-CABG. More importantly, ON-BH technology can similarly achieve coronary revascularization as C-CABG. Available evidence has indicated that complete revascularization is crucial for better long-term prognosis $(52,53)$. Tsai et al. (34) reported ON-BH CABG even appeared survival advantage in the first post-operative year compared with C-CABG. Consequently, ON-BH $\mathrm{CABG}$ is a safe and effective surgical method for coronary revascularization for high-risk patients.

Despite our research showed that ON-BH CABG had great advantages in reducing early mortality and morbidity compared with C-CABG, this surgical method also had its own limitations and indications. First of all, ONBH CABG requires modified $\mathrm{CPB}$ techniques to keep coronary perfusion pressure, negative pressure stabilizer and intracoronary shunts to maintain blood perfusion in distal region, and other technologies related to operating on the beating heart $(42,54)$. Consequently, any potential advantages afforded by ON-BH surgery may well have been lost due to the nuances of ON-BH technology and the insufficient proficiency of the surgical team (26). As mentioned above, due to the different mean arterial pressure during the operation, the results of the myocardial protection effect of ON-BH could be completely opposite. Michael and colleagues (26) found that the most favorable outcomes for ON-BH CABG came from single-centers where there may be well-developed existing technology and (or) a preference for ON-BH CABG. They reviewed the ANZSCTS (Australian \& New Zealand Society of Cardiac \& Thoracic Surgery) Database for patients undergoing emergency CABG, within 7 days of AMI, in Australia from 2001 to 2015 and found that only $1.3 \%$ (77 out of 5,851) of patients underwent ON-BH CABG across Australia. By contrast, in Japan, the proportion of emergency ONBH CABG in 2014 were $24 \%$ (480 out of 1,986$)(55)$. These figures show that $\mathrm{ON}-\mathrm{BH}$ technology is utilized far more frequently and well-developed in Japan and several early studies originate from Japan had reported more positive results than those in Australia on ON-BH CABG $(23,31,35)$. In addition, ON-BH CABG did not reduce the cost of surgery due to the use of $\mathrm{CPB}$ techniques, stabilizer and intracoronary shunt. Excessive surgery costs will increase the financial burden of poor patients. Finally, different patient benefits differently from ON-BH CABG. Our results suggest that patients with severe aortic atherosclerosis, severe coronary stenosis, acute MI, left ventricular insufficiency and renal failure are more suitable for ON-BH CABG.

There are several limitations in this research. Firstly, most of the studies included in this meta-analysis were retrospective observational studies, which may have the potential for observer bias and affect the final summary analysis of the data. In addition, there was variability in selection criteria, preoperative risk profiles and sample size between including studies. Finally, the included studies have a long-time span, and the outcomes may have been affected by developing technology and the different profiles of patients in these periods. We hoped that there would be more randomized controlled trials and longer follow-ups to evaluate the clinical efficacy of OP-BH CABG to guide clinicians to choose the most appropriate surgical method according to the patient's condition.

\section{Conclusions}

In conclusion, this meta-analysis is so far the most comprehensive and detailed research currently on the comparison between ON-BH CABG and C-CABG.

According to current evidence from our research, $\mathrm{ON}-\mathrm{BH}$ CABG might reduce early morbidity and mortality, while maintaining a comparable long-term survival as C-CABG. Patients with severe aortic atherosclerosis, acute MI, severe coronary artery stenosis and (or) renal failure may benefit more from ON-BH CABG. Experienced and adept surgical team and mature $\mathrm{ON}-\mathrm{BH}$ technology are indispensable to ensure the efficiency and success of the surgery.

\section{Acknowledgments}

Funding: None.

\section{Footnote}

Reporting Checklist: The authors have completed the 
PRISMA reporting checklist. Available at https://dx.doi. org/10.21037/jtd-21-568

Peer Review File: Available at https://dx.doi.org/10.21037/ jtd-21-568

Conflicts of Interest: All authors have completed the ICMJE uniform disclosure form (available at https://dx.doi. org/10.21037/jtd-21-568). The authors have no conflicts of interest to declare.

Ethical Statement: The authors are accountable for all aspects of the work in ensuring that questions related to the accuracy or integrity of any part of the work are appropriately investigated and resolved.

Open Access Statement: This is an Open Access article distributed in accordance with the Creative Commons Attribution-NonCommercial-NoDerivs 4.0 International License (CC BY-NC-ND 4.0), which permits the noncommercial replication and distribution of the article with the strict proviso that no changes or edits are made and the original work is properly cited (including links to both the formal publication through the relevant DOI and the license). See: https://creativecommons.org/licenses/by-nc-nd/4.0/.

\section{References}

1. Hillis LD, Smith PK, Anderson JL, et al. 2011 ACCF/ AHA Guideline for Coronary Artery Bypass Graft Surgery. A report of the American College of Cardiology Foundation/American Heart Association Task Force on Practice Guidelines. Developed in collaboration with the American Association for Thoracic Surgery, Society of Cardiovascular Anesthesiologists, and Society of Thoracic Surgeons. J Am Coll Cardiol 2011;58:e123-210.

2. Mills SA. Cerebral injury and cardiac operations. Ann Thorac Surg 1993;56:S86-91.

3. Bucerius J, Gummert JF, Walther T, et al. Impact of offpump coronary bypass grafting on the prevalence of adverse perioperative outcome in women undergoing coronary artery bypass grafting surgery. Ann Thorac Surg 2005;79:807-12; discussion 812-3.

4. Lamy A, Devereaux PJ, Prabhakaran D, et al. Effects of Off-Pump and On-Pump Coronary-Artery Bypass Grafting at 1 Year. N Engl J Med 2013;368:1179-88.

5. Keeling WB, Williams ML, Slaughter MS, et al. OffPump and On-Pump Coronary Revascularization in
Patients With Low Ejection Fraction: A Report From The Society of Thoracic Surgeons National Database. Ann Thorac Surg 2013;96:83-8.

6. Mukherjee D, Ashrafian H, Kourliouros A, et al. Intraoperative conversion is a cause of masked mortality in off-pump coronary artery bypass: a meta-analysis. Eur J Cardiothorac Surg 2012;41:291-9.

7. Perrault LP, Menasche P, Peynet J, et al. On-pump, beating-heart coronary artery operations in high-risk patients: an acceptable trade-off? Ann Thorac Surg 1997;64:1368-73.

8. Moher D, Shamseer L, Clarke M, et al. Preferred reporting items for systematic review and meta-analysis protocols (PRISMA-P) 2015 statement. Syst Rev 2015;4:1.

9. Munos E, Calderon J, Pillois X, et al. Beating-heart coronary artery bypass surgery with the help of mini extracorporeal circulation for very high-risk patients. Perfusion 2011;26:123-31.

10. Jadad AR, Moore RA, Carroll D, et al. Assessing the quality of reports of randomized clinical trials: is blinding necessary? Control Clin Trials 1996;17:1-12.

11. Stang A. Critical evaluation of the Newcastle-Ottawa scale for the assessment of the quality of nonrandomized studies in meta-analyses. Eur J Epidemiol 2010;25:603-5.

12. Furlan AD, Pennick V, Bombardier C, et al. 2009 updated method guidelines for systematic reviews in the Cochrane Back Review Group. Spine (Phila Pa 1976) 2009;34:1929-41.

13. Fumoto H, Sakata R, Nakayama Y, et al. An evaluation of coronary artery bypass grafting without aortic crossclamping due to severely atherosclerotic ascending aorta. Jpn J Thorac Cardiovasc Surg 2002;50:49-54.

14. Afrasiabirad A, Safaie N, Montazergaem H. On-pump beating coronary artery bypass in high risk coronary patients. Iran J Med Sci 2015;40:40-4.

15. Borowski A, Korb H. Myocardial infarction in coronary bypass surgery using on-pump, beating heart technique with pressure- and volume-controlled coronary perfusion. J Card Surg 2002;17:272-8.

16. Erkut B, Dag O, Kaygin MA, et al. On-pump beatingheart versus conventional coronary artery bypass grafting for revascularization in patients with severe left ventricular dysfunction: early outcomes. Can J Surg 2013;56:398-404.

17. Jalal A, Yunus A, Abualazm AMN, et al. Coronary artery bypass grafting on beating heart - Does it provide superior myocardial preservation than conventional technique? Saudi Med J 2007;28:848-54.

18. Lin CC, Wu MY, Tsai FC, et al. Prediction of major complications after isolated coronary artery bypass 
grafting: the CGMH experience. Chang Gung Med J 2010;33:370-9.

19. Lin CY, Yang TL, Hong GJ, et al. Enhanced intracellular heat shock protein 70 expression of leukocytes and serum interleukins release: comparison of on-pump and off-pump coronary artery surgery. World J Surg 2010;34:675-81.

20. Prifti E, Bonacchi M, Frati G, et al. Beating heart myocardial revascularization on extracorporeal circulation in patients with endstage coronary artery disease. Cardiovasc Surg 2001;9:608-14.

21. Kim HJ, Oh YN, Ju MH, et al. On-pump beating heart versus conventional coronary artery bypass grafting: comparative study on early and long-term clinical outcomes. J Thorac Dis 2018;10:2656-65.

22. Edgerton JR, Dewey TM, Magee MJ, et al. Conversion in off-pump coronary artery bypass grafting: an analysis of predictors and outcomes. Ann Thorac Surg 2003;76:1138-42; discussion 1142-3.

23. Miyahara K, Matsuura A, Takemura H, et al. On-pump beating-heart coronary artery bypass grafting after acute myocardial infarction has lower mortality and morbidity. J Thorac Cardiovasc Surg 2008;135:521-6.

24. Kim KB, Lim C, Lee C, et al. Off-pump coronary artery bypass may decrease the patency of saphenous vein grafts. Ann Thorac Surg 2001;72:S1033-7.

25. Yu L, Gu T, Shi E, et al. On-pump with beating heart or cardioplegic arrest for emergency conversion to cardiopulmonary bypass during off-pump coronary artery bypass. Ann Saudi Med 2014;34:314-9.

26. Zhu MZL, Huq MM, Billah BM, et al. On-Pump Beating Heart Versus Conventional Coronary Artery Bypass Grafting Early After Myocardial Infarction: A PropensityScore Matched Analysis From the ANZSCTS Database. Heart Lung Circ 2019;28:1267-76.

27. Uva MS, Rodrigues V, Monteiro N, et al. Coronary surgery: which method to use? Rev Port Cardiol 2004;23:517-30.

28. Sabban MA, Jalal A, Bakir BM, et al. Comparison of neurological outcomes in patients undergoing conventional coronary artery bypass grafting, on-pump beating heart coronary bypass, and off-pump coronary bypass. Neurosciences (Riyadh) 2007;12:35-41.

29. Narayan P, Rogers CA, Bayliss KM, et al. On-pump coronary surgery with and without cardioplegic arrest: comparison of inflammation, myocardial, cerebral and renal injury and early and late health outcome in a singlecentre randomised controlled trial. Eur J Cardiothorac Surg 2011;39:675-83.
30. Chen SW, Chang CH, Chu Y, et al. Postoperative Renal Outcomes of On-Pump Beating-Heart versus Cardioplegic Arrest Coronary Artery Bypass Grafting. Acta Cardiol Sin 2017;33:542-50.

31. Mizutani S, Matsuura A, Miyahara K, et al. On-pump beating-heart coronary artery bypass: a propensity matched analysis. Ann Thorac Surg 2007;83:1368-73.

32. Pegg TJ, Selvanayagam JB, Francis JM, et al. A randomized trial of on-pump beating heart and conventional cardioplegic arrest in coronary artery bypass surgery patients with impaired left ventricular function using cardiac magnetic resonance imaging and biochemical markers. Circulation 2008;118:2130-8.

33. Quan XQ, Cheng ZY, Sun JJ, et al. Effects of on-pump beating-heart coronary artery bypass grafting for left-main patients. Zhonghua Yi Xue Za Zhi 2013;93:2545-8.

34. Tsai YT, Lin FY, Lai CH, et al. On-pump beating-heart coronary artery bypass provides efficacious short- and long-term outcomes in hemodialysis patients. Nephrol Dial Transplant 2012;27:2059-65.

35. Izumi $Y$, Magishi K, Ishikawa N, et al. On-pump beatingheart coronary artery bypass grafting for acute myocardial infarction. Ann Thorac Surg 2006;81:573-6.

36. Chaudhry UA, Harling L, Sepehripour AH, et al. BeatingHeart Versus Conventional On-Pump Coronary Artery Bypass Grafting: A Meta-Analysis of Clinical Outcomes. Ann Thorac Surg 2015;100:2251-60.

37. Landymore R, Spencer F, Colvin S, et al. Management of the calcified aorta during myocardial revascularization. J Thorac Cardiovasc Surg 1982;84:455-6.

38. Rastan AJ, Eckenstein JI, Hentschel B, et al. Emergency coronary artery bypass graft surgery for acute coronary syndrome: beating heart versus conventional cardioplegic cardiac arrest strategies. Circulation 2006;114:I477-85.

39. Newman MA, Chen XZ, Rabinov M, et al. Sensitivity of the recently infarcted heart to cardioplegic arrest. Beneficial effect of pretreatment with orotic acid. J Thorac Cardiovasc Surg 1989;97:593-604.

40. Gudbjarnason S, Puri PS, Mathes P. Biochemical changes in non-infarcted heart muscle following myocardial infarction. J Mol Cell Cardiol 1971;2:253-76.

41. Varatharajah K, Rosenfeldt FL. Changes in noninfarcted myocardium explain benefits of on-pump beating-heart coronary artery bypass grafting for acute myocardial infarction. J Thorac Cardiovasc Surg 2009;137:1575-6; author reply 1576-7.

42. Ueki C, Sakaguchi G, Akimoto T, et al. On-pump beatingheart technique is associated with lower morbidity and 
mortality following coronary artery bypass grafting: a meta-analysis. Eur J Cardiothorac Surg 2016;50:813-21.

43. Boodhwani M, Rubens FD, Wozny D, et al. Effects of mild hypothermia and rewarming on renal function after coronary artery bypass grafting. Ann Thorac Surg 2009;87:489-95.

44. Billings FT 4th, Ball SK, Roberts LJ 2nd, Pretorius

M. Postoperative acute kidney injury is associated with hemoglobinemia and an enhanced oxidative stress response. Free Radic Biol Med 2011;50:1480-7.

45. Newland RF, Baker RA, Mazzone AL, et al. Rewarming Temperature During Cardiopulmonary Bypass and Acute Kidney Injury: A Multicenter Analysis. Ann Thorac Surg 2016;101:1655-62.

46. Rothenburger M, Tjan TD, Schneider M, et al. The impact of the pro- and anti-inflammatory immune response on ventilation time after cardiac surgery. Cytometry B Clin Cytom 2003;53:70-4.

47. Shroyer AL, Hattler B, Wagner TH, et al. Five-Year Outcomes after On-Pump and Off-Pump CoronaryArtery Bypass. N Engl J Med 2017;377:623-32.

48. Chikwe J, Lee T, Itagaki S, et al. Long-Term Outcomes After Off-Pump Versus On-Pump Coronary Artery Bypass Grafting by Experienced Surgeons. J Am Coll Cardiol 2018;72:1478-86.

Cite this article as: Wang C, Jiang Y, Jiang X, Chen S. Onpump beating heart versus conventional on-pump coronary artery bypass grafting on clinical outcomes: a meta-analysis. J Thorac Dis 2021;13(7):4169-4184. doi: 10.21037/jtd-21-568
49. Takagi H, Ando T, Mitta S, et al. Meta-Analysis Comparing $\geq 10$-Year Mortality of Off-Pump Versus OnPump Coronary Artery Bypass Grafting. Am J Cardiol 2017;120:1933-8.

50. Légaré JF, Buth KJ, Hirsch GM. Conversion to on pump from $\mathrm{OPCAB}$ is associated with increased mortality: results from a randomized controlled trial. Eur J Cardiothorac Surg 2005;27:296-301.

51. Kazui T, Osada H, Fujita H, et al. Thoracic and cardiovascular surgery in Japan during 2004. Jpn J Thorac Cardiovasc Surg 2006;54:363-85.

52. Lattouf OM, Thourani VH, Kilgo PD, et al. Influence of on-pump versus off-pump techniques and completeness of revascularization on long-term survival after coronary artery bypass. Ann Thorac Surg 2008;86:797-805.

53. Synnergren MJ, Ekroth R, Oden A, et al. Incomplete revascularization reduces survival benefit of coronary artery bypass grafting: Role of off-pump surgery. J Thorac Cardiovasc Surg 2008;136:29-36.

54. Mo A, Lin H. On-pump Beating Heart Surgery. Heart Lung Circ 2011;20:295-304.

55. Masuda M, Okumura M, Doki Y, et al. Thoracic and cardiovascular surgery in Japan during 2014 Annual report by The Japanese Association for Thoracic Surgery. Gen Thorac Cardiovasc Surg 2016;64:665-97. 